\title{
SINDICALISMO DO ABC E A ERA LULA: CONTRADIÇÕES E RESISTÊNCIAS ${ }^{1}$
}

\section{José Ricardo Ramalho ${ }^{a}$}

aé professor do Departamento de Sociologia e do Programa de Pós-Graduação em Sociologia e Antropologia (PPGSA) da Universidade Federal do Rio de Janeiro (PPGSA-UFRJ).

Rio de Janeiro, RJ, Brasil. E-mail: <josericardoramalho@gmail.com>

Orcid: $0000-0002-4855-6687$

Iram Jácome Rodrigues ${ }^{b}$

'é professor do Departamento de Economia e do Programa de Pós-Graduação em Sociologia da Universidade de São Paulo (PPGS-USP). São Paulo, SP, Brasil.

E-mail:<iramjrodrigues@gmail.com>

Orcid: 0000-0002-5593-2505

http://dx.doi.org/10.1590/0102-067096/104

\section{Introdução}

A resistência sindical à ditadura militar de 1964, que se consolidou no ABC Paulista a partir das greves de 1978, 1979,1980 , teve na categoria metalúrgica um de seus principais expoentes, e as estratégias de confronto político que marcaram esse período inovaram no formato e no nível de organização dos trabalhadores em comparação com experiências anteriores ocorridas no país. Entre as principais características da resistência se destacaram o trabalho de base, mesmo sob a ameaça de uma repressão policial que se manifestou dentro das próprias fábricas ${ }^{2}$,

\footnotetext{
1 Este artigo se beneficia de resultados de pesquisa e projetos dos autores apoiados pelo CNPQ e pela Faperj (Cientistas do Nosso Estado). Agradecemos ao Jonas Tomazi Bicev pelo tratamento estatístico dos dados do Relatório Anual de Informações Sociais do Ministério do Trabalho e Previdência Social (RAIS-MTPS).

2 O caso da Volkswagen de São Bernardo, revelado recentemente, confirma e elucida uma participação direta de diretorias de empresas multinacionais nos processos de perseguição e tortura de trabalhadores. Ver matéria do Jornal do Brasil: “'Der Spiegel': Volkswagen espionou e torturou funcionários durante ditadura no Brasil", disponível em: <https://bit.ly/2mudNAE >. Acesso em: 18 jun. 2018.
} 
e a ampla solidariedade que essa articulação angariou junto a outros movimentos sociais.

A crítica ao autoritarismo do governo e a uma legislação trabalhista restritiva acabou tendo um efeito multiplicador e renovador das ações sindicais que tradicionalmente eram controladas pelo Ministério do Trabalho. Esse movimento que, na época, ganhou o nome de "novo sindicalismo"', mudou a conjuntura brasileira das últimas décadas e, nesse processo, foi mola propulsora do surgimento da Central Única dos Trabalhadores (CUT) e do Partido dos Trabalhadores (PT).

Internacionalmente, nos anos 1990, o sindicalismo do ABC virou exemplo de um "sindicato de tipo movimento social" (social movement unionism, em inglês), e foi identificado como alternativa crítica a um sindicalismo mais burocrático e em crise existente na Europa e nos EUA, principalmente porque se associava a outras formas de organização popular na luta por melhores condições de vida e de defesa dos trabalhadores.

A eleição de Luiz Inácio Lula da Silva - principal liderança sindical do ABC Paulista - para a presidência do Brasil em 2002, e sua permanência no cargo por oito anos (20032010), foi a confirmação da força política desse sindicalismo que estabeleceu novos parâmetros e influenciou decisivamente os rumos da organização dos trabalhadores no país. A presença de Lula no cargo máximo da República proporcionou também a criação de uma agenda diferenciada na relação entre governo e movimento sindical, com a implementação de mecanismos até então pouco experimentados de participação social e a necessidade de articular maior apoio político.

A derrota política desse projeto e da aproximação com o movimento sindical, após o impeachment da ex-presidente Dilma Rousseff, em 2016, e a prisão de Lula, em 2018, teve

\footnotetext{
${ }^{3}$ Ver, entre outros, Jácome Rodrigues (1999, 2011).
} 
um desfecho trágico. Mas foi na sede do Sindicato dos Metalúrgicos do ABC, rodeado por diferentes gerações de sindicalistas formados sob sua inspiração, que o ex-presidente fez um discurso emblemático, tomando como exemplo a história de luta dos trabalhadores brasileiros, para atacar o desmonte de direitos e garantias legais. Nesse episódio, o atual presidente do Sindicato dos Metalúrgicos, Wagner Santana, ligou para Lula e disse: "o sindicato está aqui à disposição". E completou: "é o ambiente em que ele se sente bem, o ambiente em que ele cresceu para o mundo e para a política". Para o dirigente, "é difícil sentar nessa cadeira. A responsabilidade de ser presidente desse sindicato, com a história desse sindicato, é assustadora. [...]. É um sindicato que tem um peso, um nome, pela história, pela figura que é o próprio Luiz Inácio"4.

A proposta deste texto é tentar, a partir de um levantamento de dados estatísticos referentes ao trabalho e ao emprego na região do ABC Paulista, estabelecer uma relação entre o contexto econômico e político do período governado por Lula/Dilma e as estratégias sindicais dos metalúrgicos, levando em conta as ligações políticas evidentes com o governo do PT e, principalmente, com o presidente operário. A intenção é avaliar, como resultado dessa proximidade, a existência de avanços e/ou recuos nas práticas de luta do sindicato para obter melhores salários, criar novas oportunidades de emprego, aumentar a atuação junto à sociedade civil e buscar interferir no debate sobre estratégias de desenvolvimento regional ${ }^{5}$.

\footnotetext{
${ }^{4}$ Entrevista com Wagner Santana, "A responsabilidade assustadora”, UOL Notícias. Disponível em: <https://bit.ly/2L5MdIB >. Acesso em: 31 maio 2018.

${ }_{5}$ Em 2017, o Grande ABC tinha um contingente populacional de 2.753 .376 habitantes, pouco mais de $1 \%$ da população brasileira e cerca de $6 \%$ dos habitantes do estado de São Paulo. Esse contingente populacional é composto pelos municípios de Santo André, São Bernardo do Campo, São Caetano do Sul, Diadema, Mauá, Ribeirão Pires e Rio Grande da Serra (Instituto Brasileiro de Geografia e Estatística, 2017). Em 2012, o PT perdeu a Prefeitura de Diadema, que governava
} 


\section{Estratégias sindicais e os diferentes contextos}

As estratégias adotadas pelo Sindicato dos Metalúrgicos do ABC, nas décadas subsequentes ao fim da ditadura militar de 1964, revelam os mesmos dilemas enfrentados por sindicatos de outros países, exigindo que se tome como essencial para qualquer análise considerações sobre as especificidades de tempo e de espaço.

Para Fairbrother e Webster (2008, p. 310), "programas e estratégias sindicais se desenvolvem em contextos sociais, econômicos e políticos particulares". Segundo esses autores, essa é a melhor maneira de "entender não apenas os limites e possibilidades da organização e operação do sindicato, mas o modo como as tensões aparecem nesses contextos".

Nos anos 1990, o sindicato dos metalúrgicos se defrontou com um contexto econômico atingido pela globalização e por uma "reestruturação produtiva" que flexibilizou relações de trabalho e afetou as empresas da região do $\mathrm{ABC}^{6}$. $\mathrm{O}$ 70 resultado foi a adoção de uma ação sindical defensiva como modo de preservar empregos e atividades econômicas. Essa mesma postura se repetiu com a crise econômica e financeira de 2008 (Rodrigues e Ramalho, 2009).

De lá para cá, o contexto do "novo sindicalismo" se alterou substantivamente - foi obrigado a criar novas estratégias e a se reestruturar politicamente, mas não deixou de ser ativo e de articular novas demandas. E fez uso desse capital político, durante as crises econômicas, para construir canais de negociação com entidades patronais e administração pública e para introduzir uma pauta de reivindicações voltada para as questões sociais e econômicas

desde 1985. Em contrapartida, além de ter sido reeleito em São Bernardo, ganhou em Santo André e em Mauá. O total de habitantes nessas três cidades governadas pelo PT correspondia a $73 \%$ do total dos habitantes da região do Grande ABC. Esse quadro novamente se altera com a eleição de 2016, quando os candidatos do PT foram derrotados pelos partidos de oposição.

${ }^{6}$ Cf., entre outros, Conceição (2008). 
da região. Sua reação foi proativa, diante dos efeitos sociais negativos impostos pela nova realidade produtiva.

Em textos anteriores (Ramalho e Rodrigues, 2010, 2013; Ramalho, Rodrigues e Conceição, 2009) detalhamos essas diferentes formas de enfrentar crises que se consolidaram ao longo da década de 2000.

Apesar da gestão Lula ter mantido, em termos macroeconômicos, as linhas mestras de um padrão mundial de economias globalizadas, estabeleceu, ao mesmo tempo, novos canais de participação e de políticas sociais voltadas a atender os trabalhadores e os mais pobres. No que se refere ao trabalho, tentativas de reforma da legislação trabalhista e sindical não funcionaram, entre outras razões, pela necessidade de obter consenso em sua base política de apoio no Congresso Nacional, e o relacionamento entre o governo e os sindicatos acabou, ao longo dos anos 2000, por se caracterizar por apoio e por divergências e conflitos.

Pretendemos, ao longo do texto, mostrar dados e trabalhar com a hipótese de que o padrão sindical dos metalúrgicos do ABC, ao se beneficiar das ligações políticas com instâncias do poder, se consolida e usa as novas práticas para, de um lado, proteger os interesses dos trabalhadores que representa e, de outro, vocalizar as demandas do conjunto da população da região onde está inserido ${ }^{7}$.

Dito de outra forma, o sindicalismo metalúrgico no ABC adotou a postura de que, no atual estágio das relações entre capital e trabalho na região, a melhor forma de defesa dos interesses específicos de sua categoria seria colocá-la também como parte dos interesses mais gerais daquelas demandas relacionadas à cidade, à região. Com essa estratégia buscou legitimar sua atividade em setores da sociedade civil e a própria instituição sindical (Waterman, 1999, pp. 260-261).

7 O Sindicato dos Metalúrgicos do ABC abrange, hoje, quatro dos sete municípios do Grande ABC: São Bernardo do Campo, Diadema, Ribeirão Pires e Rio Grande da Serra. 
Essa opção político-sindical não está isenta de contradições, haja vista as experiências relativas à ligação de sindicatos com governos trabalhistas, já ocorridas e debatidas em outros países e em outros contextos. No entanto, pode servir de base comparativa para identificar a combinação entre avaliações teóricas gerais e os contextos históricos particulares onde estão inseridos os sindicatos.

\section{Sindicato e região}

Em estudo publicado no início dos anos 2000, que retrata as mudanças ocorridas na paisagem socioeconômica da região do ABC na segunda metade do século XX, Allen Scott (2000, p. 7) chama atenção para o fato de a região do $\mathrm{ABC}$ ter se constituído, logo após a Segunda Guerra Mundial, "como o primeiro centro de produção fordista do Brasil e seu crescimento foi especialmente acentuado após meados da década de 1950, quando a indústria automobilística do País começou a se desenvolver mais intensamente".

Os anos 1960 e 1970 e parte dos 1980 foram de crescimento acelerado e trouxeram prosperidade e avanço para o ABC, transformando-o no "centro mais desenvolvido de atividades de fabricação avançada do país" (Scott, 2000, p. 7). No entanto, já em meados dos anos 1980, a economia da região colocou em dúvida suas potencialidades. "De forma muito parecida com os casos anteriores dos centros industriais fordistas da América do Norte e Oeste Europeu na década de 1970, o avanço econômico da região do ABC estava ameaçado por uma combinação de altos salários, sindicatos militantes, valores de terras em ascensão [crescimento urbano desordenado] etc." (Scott, 2000, p. 7). Para o autor, as novas condições criam um momento político, "em que todos se unem em busca de soluções e, especialmente, de um novo modelo de desenvolvimento e crescimento econômico local” (Scott, 2000, p. 7). 
Esse é o pano de fundo de atuação do Sindicato dos Metalúrgicos do ABC, que envolvia uma dinâmica entre diversos atores sociais, com destaque para a disputa entre as empresas montadoras e de autopeças e a ação organizada dos trabalhadores. Nessa fase, a ação sindical, que desde os anos 1970 tem situado o espaço fabril como o privilegiado da contenda entre o capital e o trabalho, a partir da década de 1990 se volta também à discussão de temas relacionados à regionalidade, ao desenvolvimento local, regional e à formulação e implementação - junto com outros atores sociais e políticos - de políticas públicas voltadas para esse território.

Os usos de novas práticas reivindicatórias não desconheceram os conflitos estruturais entre capital e trabalho e as questões de classe, mas se aproximaram da sociedade por meio de demandas que vão além das questões corporativas e se colocam para a população trabalhadora como um todo (Rodrigues, 2006).

Durante a década de 2000, no período dos mandatos de Lula, as greves continuaram no setor metalúrgico, houve aumento real de salário - principalmente nas grandes empresas automotivas - o poder da pressão sindical foi extremamente forte e organizado, e a prática democrática de representação nas fábricas foi mantida e ampliada, na orientação consolidada pelos conflitos dos anos 1970 e 1980.

\section{Sindicato e política}

A experiência de um movimento sindical europeu, também atingido pela reestruturação produtiva, flexibilização das relações de trabalho e estratégias de globalização, pode fornecer elementos para refletir sobre o movimento sindical do ABC. Nesse sentido, lançamos mão da contribuição de Hyman e Gumbrell-McCormick (2001) no que diz respeito às possibilidades de ação política dos sindicatos. Para os autores, mercado, classe e sociedade seriam a 
"geometria do sindicalismo", conectados em um balanço instável dos três pontos do triângulo (Hyman e GumbrellMcCormick, 2001, pp. 3-4). O sindicalismo com foco no mercado, na sociedade e na classe nunca existiria na forma pura e na prática: "os sindicatos hoje tendem a se inclinar para uma mistura desses três tipos ideais".

Essa interpretação sobre as diversas manifestações do sindicato reforça argumentos que consideram posições políticas e estratégias sindicais como fruto de avaliações permeadas pelos contextos locais, regionais e nacionais, de tradições políticas incorporadas historicamente às práticas sindicais, de conjunturas econômicas globais e nacionais e seus desdobramentos sobre o mercado de trabalho e aumento do desemprego. Isso não significa esquecer a questão de classe e das relações de classe que, na verdade, definem o sindicalismo.

Para Hyman e Gumbrell-McCormick (2001, p. 4), sin74 dicatos que representam os interesses dos trabalhadores em confronto com os interesses dos empregadores são também "agências de classe", e essa característica coloca em questão, em todo momento, uma tensão entre exercer sua prática como movimento (movimentos de classe e movimentos populares) - e a institucionalização, que implica em uma acomodação dos interesses de classe dentro das instituições.

No entanto, para os autores (2001, p. 36), o sindicalismo com base na classe é ilusório: "O 'grande sindicato único' organizando trabalhadores de todos os tipos em suas fileiras nunca foi mais do que um sonho; os sindicatos atuais dividem ao mesmo tempo em que unem. E, enquanto os sindicatos podem se engajar em conflito, eles também regulam e normatizam a relação de trabalho”. E prosseguem:

os sindicatos, através de suas ações, mesmo que de oposição, se misturaram a sistemas de inter-relacionamentos que, ao menos parcialmente, os integram à sociedade; e através de 
suas conquistas, econômicas e políticas, se tornam partes interessadas em defender elementos da ordem social ${ }^{8}$ (Hyman e e Gumbrell-McCormick, 2001, pp. 38-39).

E, no que diz respeito à capacidade de exercer influência sobre o mercado, "os sindicatos têm que se dirigir ao estado e, como modo de assegurar a relevância de uma 'economia moral' alternativa, devem participar na sociedade civil” (Hyman e Gumbrell-McCormick, 2001, p. 16).

Na avaliação de Fairbrother e Webster (2008, p. 310), "os sindicatos são um tipo de movimento social que contém dimensões progressistas e acomodatícias", e a questão que se coloca para os analistas é identificar "como e em que circunstâncias os sindicatos podem desafiar e questionar a relação capital/trabalho". Para esses autores, cabe aos sindicatos, como associações de trabalhadores, regular a relação salário-trabalho e, por essa razão, não podem ignorar o mercado. Mas os sindicatos "são também parte da sociedade, coexistindo com outras instituições e outras constelações de interesses".

8 Para Hyman e Gumbrell-McCormick (2001, p. 29) "a posição marxista clássica é a de que a participação na luta de classes fortaleceria o entendimento dos trabalhadores sobre interesses comuns com outros trabalhadores e seu antagonismo com os empregadores (e também, na maioria dos casos, com o Estado). Assim, greves e outras formas de ação de oposição seriam componentes essenciais da atividade sindical anticapitalista. Muitos socialistas de esquerda no início do século XX se opuseram como um todo à noção de negociação coletiva, já que os acordos feitos com os empregadores restringiriam a capacidade dos trabalhadores de resistir à exploração de seus empregadores. [...] De novo, a experiência frequentemente indica que esses assuntos são mais complicados. Os sindicatos que aproveitam toda a oportunidade para lutar contra o empregador podem esperar retaliação; em outros momentos, distintos daqueles de tumulto social e político, a maioria dos trabalhadores provavelmente não estará disposta a aceitar por muito tempo os custos da ação sindical, e o resultado provável é derrota e desmoralização. Um negociador sindical, na famosa frase de Wright Mills (1948, pp. 8-9), age como um "gerente do descontentamento": mobilizando as reclamações e aspirações de modo a colocar pressão sobre o empregador, mas então restringindo a ação disruptiva para proteger a relação de negociação. As pressões para combinar ordem com militância são experimentadas pelos ativistas de base assim como pelos dirigentes, por radicais políticos bem como por moderados". 
A prática sindical dos metalúrgicos do $\mathrm{ABC}$ de valorizar outros espaços institucionais representa uma mudança de estratégia devido ao impacto sobre o emprego do processo de reestruturação produtiva e confirma uma postura de "cooperação conflitiva" que marca essa nova conjuntura (Rodrigues, 1995). Segundo Oliveira (2011), na década de 1990 o sindicalismo do ABC buscou uma nova forma de inserção na sociedade, diversificou sua agenda de preocupações e ampliou sua participação em espaços públicos. A ideia era a de um sindicato "que não se fecha no horizonte corporativo de uma categoria", mas atua como "sujeito social em luta pela cidadania" (Oliveira, 2011, p. 270).

Uma leitura dos dados sobre os períodos Lula (e Dilma) demonstra que o ciclo desses governos de perfil trabalhista não só foi positivo em termos de desempenho político voltado para os setores mais pobres da população brasileira - confirmando sua trajetória de trabalhador e sindicalista - como significou a chegada ao poder de um setor da sociedade tradicionalmente marginalizado. Como diz Cardoso (2016, p. 130):

é verdade que o PT e a CUT abandonaram seu estrito discurso socialista, mas a consequência de um processo de decisão política participativo foi a implementação de um projeto de inclusão universal na dinâmica capitalista através da melhoria das condições de vida do pobre, uma inclusão massiva das classes médias baixas e estratos mais pobres no mercado de consumo através de mecanismos de crédito subsidiado, redistribuição de renda, crescimento econômico e, mais importante de tudo, a criação de empregos.

Mesmo considerando que não houve alterações em questões importantes para os sindicatos e para os trabalhadores - como a manutenção na CLT da unicidade e do imposto sindical -, e que a decisão positiva do projeto de legalização das centrais sindicais aprovado por Lula pode ter tido o efeito de relaxar nas novas tentativas de reformar 
a legislação trabalhista, Cardoso (2016, pp. 136-137) ressalta que Lula trouxe de volta o Estado de dois modos importantes com relação direta para a vida dos trabalhadores:

primeiro, a administração do PT re-politizou parcialmente a economia. Os pilares macroeconômicos do neoliberalismo estão ainda protegidos das disputas políticas, mas o Estado se tornou uma máquina central de crescimento econômico ao investir diretamente em infraestrutura e financiando o investimento privado de várias maneiras. Em segundo lugar, o Estado é novamente o principal mecanismo de coordenação da sociabilidade capitalista, um lugar que o neoliberalismo tinha cedido ao mercado.

Para o autor, "isto não é retórica política. Ao oferecer à população como um todo um projeto macroeconômico de inclusão e segurança, e lutando com as forças de oposição para implementá-lo, o Estado novamente alimentou nos trabalhadores aspirações e expectativas" (Cardoso, 2016, pp. 136-137).

Fortes e French (2012, p. 213) vão nessa mesma direção ao afirmar que "tendo liderado greves maciças dos 'peões' da indústria metalúrgica, Lula aprendeu que a batalha decisiva é pela massa de uma determinada base social, não por sua minoria politizada”. Em 1991, ele destacava que o objetivo do PT deveria ser "alcançar o segmento da sociedade que ganha um salário mínimo ou menos” (Silva, 1991, p. 8 apud Fortes e French, 2012). Para esses autores, "os anos Lula viram dezenas de milhões de brasileiros serem integrados à plena cidadania como trabalhadores, consumidores mais ativos e pessoas cuja titularidade a direitos foi fortalecida" (Fortes e French, 2012, p. 221).

Para Singer (2009, p. 94), as ações governamentais foram “muito além de simples 'ajuda' aos pobres”. Ele afirma que 
o aumento do salário mínimo, a expansão do crédito popular com aumento da formalização do trabalho [...] e a transferência de renda, aliados à contenção de preços, sobretudo da cesta básica [dão uma orientação política principalmente para os setores de baixa renda.] Nesse sentido, tais ações colocam Lula à frente de um projeto, que é compatível com aspectos de sua biografia (Singer, 2009, p. 94).

Para Anderson (2011, p. 31), o exemplo da crise econômica de 2008 serve para ressaltar a postura de Lula na economia:

foi nesse momento que ele declarou que a quebra de Wall Street em 2008 pode ter sido um tsunami para os EUA, mas no Brasil ela estava mais para uma "marolinha". [...] As medidas de contenção foram imediatas e eficazes. Apesar da queda na arrecadação fiscal, a distribuição de renda aumentava, as reservas foram reduzidas, o investimento público subiu e o consumo doméstico foi amparado. [...] Foi a política de Estado vigorosa e orquestrada que manteve a economia saudável.

A presença de partidos de cunho trabalhista no poder tem representado historicamente oportunidades para o avanço das pautas sindicais e das políticas sociais e econômicas favoráveis aos trabalhadores e aos setores mais pobres da população. No entanto, os desafios colocados pela globalização e as mudanças na estrutura social, segundo Martins Rodrigues (1999, pp. 238239), fizeram os velhos "partidos da classe operária" buscarem novos segmentos do eleitorado e, quando no governo, adotarem estratégias de "partido do governo". As indicações mais fortes, segundo o autor, apontam para a constatação que "a existência de partidos de esquerda ou centro-esquerda no governo tende a favorecer o sindicalismo, enquanto a existência de governos de direita tende a lhe ser prejudicial" (Martins Rodrigues, 1999, pp. 238-239). 


\section{Atividade econômica regional}

Os dados sobre a região do $\mathrm{ABC}$, referentes às décadas de 1990, 2000 e parte de 2010, permitem identificar avanços e recuos na dinâmica social e econômica regional, 0 o perfil da mão de obra. Entre 1985 e 2016, o número de estabelecimentos de pequeno porte (de 0 a 99 empregados) saltou de 15.422 para 46.964 estabelecimentos. Ao mesmo tempo, a quantidade de empresas de médio e grande porte variou muito pouco; chegam a cair na segunda metade da década de 1990 e crescem a partir de 2005, somando 778 estabelecimentos de médio porte e 131 estabelecimentos de grande porte no ano de 2016 (Tabela 1).

\section{Tabela 1}

Número de estabelecimentos segundo o número de empregados (Grande ABC, 1985-2016)

\begin{tabular}{lcccc}
\hline Ano & $\begin{array}{c}\text { Empresa de pequeno } \\
\text { porte (de 0 até 99 } \\
\text { empregados) }\end{array}$ & $\begin{array}{c}\text { Empresa de médio } \\
\text { porte (de 100 a 499 } \\
\text { empregados) }\end{array}$ & $\begin{array}{c}\text { Empresa de grande } \\
\text { porte (500 ou mais } \\
\text { empregados) }\end{array}$ & Total \\
\hline 1985 & 15.422 & 692 & 135 & 16.249 \\
\hline 1990 & 21.670 & 709 & 144 & 22.523 \\
\hline 1996 & 25.405 & 649 & 112 & 26.166 \\
\hline 2000 & 29.511 & 618 & 117 & 30.246 \\
\hline 2006 & 36.068 & 728 & 152 & 36.948 \\
\hline 2010 & 42.592 & 906 & 181 & 43.679 \\
\hline 2016 & 46.964 & 778 & 131 & 47.873 \\
\hline
\end{tabular}

Fonte: Elaboração própria com base nos dados do MTPS da Rais Estabelecimentos dos anos selecionados ${ }^{9}$.

\section{Perfil do emprego}

Em relação às transformações do emprego formal na região (vínculos ou contratos de trabalho ativos no dia $31 \mathrm{de}$

${ }^{9}$ Disponível em: <https://bit.ly/2OAQB0n>. Acesso em: 25 jul. 2018. 
dezembro de cada ano), os dados confirmam o crescimento da formalização, especialmente durante o período Lula. Mais detalhadamente, houve três momentos: um primeiro, entre 1985-1988, com crescimento moderado do emprego, seguido de uma queda constante até 1993 - quando a região enfrenta os impactos da abertura econômica de 1991 e registra o mais baixo nível de emprego dos últimos 30 anos (467.474 vínculos de trabalho). Um segundo, de estagnação e crise, decorrentes da reestruturação das empresas e das políticas de estabilização monetária, que, a partir de 1999, começa a se reverter e inaugura um terceiro ciclo, durante os governos do PT, de grande expansão econômica e criação de postos de trabalho formais (Gráfico 1).

Gráfico 1

Trabalhadores formais segundo o setor de atividade econômica

(Grande ABC, 1985-2016)

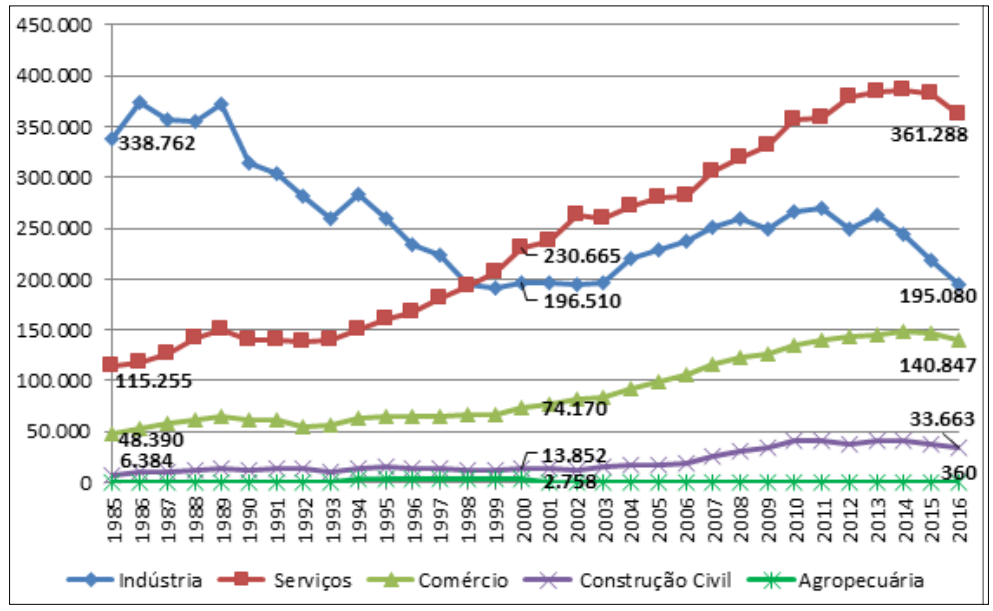

* Vínculos ativos no dia 31 de dezembro.

Fonte: Elaboração própria com base nos dados do MTPS da Rais -

Estabelecimentos dos anos selecionados ${ }^{10}$.

${ }^{10}$ Disponível em: <https://bit.ly/2OAQB0n>. Acesso em: 25 jul. 2018. 
No que tange à composição setorial do emprego, coerentemente com a mudança no perfil dos estabelecimentos, a importância do setor industrial se reduz e sua participação na totalidade dos empregos cai de 66\%, em 1985 (338.762 trabalhadores), para (27\%), em 2016 (195.080 trabalhadores). Em contrapartida, o setor de serviços aumenta sua participação e, em 2016, passou a representar, praticamente, a metade dos empregos (49\%), isto é, 361.288 trabalhadores no ABC, seguido do comércio com $19 \%$ dos empregos (140.847 trabalhadores). Vale dizer que quase $70 \%$ das ocupações formais em 2016 correspondiam ao setor terciário.

Se o crescimento do setor de serviços e a proliferação de estabelecimentos de micro ou pequeno porte, por um lado, parecem minimizar os efeitos do desemprego na região, também, em alguma medida, reduzem o papel desempenhado pela grande empresa industrial historicamente estabelecida no Grande ABC. Empregos de longa duração, com benefícios e remunerações acima da média, que sempre foram um grande atrativo da região, foram ameaçados, assim como as demandas salariais e o modelo de relações de trabalho das indústrias.

\section{Metalúrgicos ${ }^{11} \mathrm{e}$ a questão salarial}

Quando observamos os dados sobre a evolução do estoque de empregos metalúrgicos nos sete municípios do Grande ABC e os comparamos com a evolução do emprego metalúrgico no Estado de São Paulo e no Brasil, o que chama atenção é uma queda acentuada no Grande ABC e um decréscimo, em menor grau, no Estado de São Paulo. A despeito do crescimento do emprego metalúrgico em geral no

11 Para contornar as dificuldades decorrentes das mudanças na Classificação Brasileira de Ocupações (CBO), nesta seção, classificamos como metalúrgicos os vínculos de trabalho ativo no Rais dos Subsetores de Atividade 3 a 6 do IBGE (período 1985-1994); das divisões 27 a 35 da Classificação Nacional de Atividades Econômicas (Cnae, período 1995-2005); e divisões 24 a 30 e 33 da Cnae 2.0 (de $2006 \mathrm{em}$ diante). A escolha desses setores industriais justifica-se pelo predomínio dos metalúrgicos entre os seus empregados. 
país, principalmente no período do segundo governo Lula, o que os dados mostram para o período (1985-2016) é a "estagnação" do emprego metalúrgico em termos nacionais.

Além disso, os dados da Tabela 2 demonstram que a região do Grande $\mathrm{ABC}$ perdeu quase 115 mil trabalhadores metalúrgicos em relação ao que possuía em $1985^{12}$. Tudo isso contribuiu para reduzir a participação relativa do Grande ABC no total de metalúrgicos empregados no país.

Tabela 2

Número de metalúrgicos empregados no Brasil, no estado de São Paulo e no Grande ABC, 1985-2016 (vínculos ativos no dia 31 de dezembro de cada ano)

\begin{tabular}{cccc}
\hline Ano & $\begin{array}{c}\text { Metalúrgicos } \\
\text { Brasil }\end{array}$ & $\begin{array}{c}\text { Metalúrgicos } \\
\text { Estado de São Paulo }\end{array}$ & $\begin{array}{c}\text { Metalúrgicos } \\
\text { Grande ABC }\end{array}$ \\
\hline 1985 & 1.637 .240 & 1.026 .244 & 216.400 \\
\hline 1990 & 1.644 .803 & 992.918 & 176.817 \\
\hline 1996 & 1.318 .502 & 727.588 & 130.647 \\
\hline 2000 & 1.276 .699 & 672.457 & 106.775 \\
\hline 2006 & 1.777 .608 & 859.438 & 128.311 \\
\hline 2010 & 2.268 .733 & 1.040 .155 & 148.227 \\
\hline 2016 & 1.877 .233 & 800.146 & 102.096 \\
\hline
\end{tabular}

Fonte: Elaboração própria com base nos dados do MTPS da Rais Estabelecimentos dos anos selecionados ${ }^{13}$.

A redução no contingente de metalúrgicos, no entanto, não alterou as diferenças salariais com relação à média salarial no estado de São Paulo e no Brasil. A força política e organizacional do sindicato dos metalúrgicos do $\mathrm{ABC}$ se confirma nesse quesito e, mesmo com a queda no poder de compra dos salários, no ano de 2016, a média salarial dos metalúrgicos no Grande ABC ultrapassava em mais de $\mathrm{R} \$ 1.700,00$ a média brasileira e de quase $\mathrm{R} \$ 1.200,00$ a média do estado de São Paulo (Tabela 3).

\footnotetext{
12 Cabe ressaltar que a maioria desses empregos foi eliminada durante a década de 1990. Segundo os dados da RAIS, MTPS, entre 1990 e 1999, foram eliminados 441.927 empregos metalúrgicos em todo o Brasil. Só no estado de São Paulo foram fechados 360.140 postos de trabalho metalúrgicos, enquanto no Grande $\mathrm{ABC}$ a perda foi de 73.078 postos. Disponível em: <https://bit.ly/2OAQB0n>. Acesso em: 25 jul. 2018.

${ }^{13}$ Disponível em: <https://bit.ly/2OAQB0n>. Acesso em: 25 jul. 2018.
} 
Tabela 3

Média salarial dos metalúrgicos do Brasil, do estado de São Paulo e do Grande ABC, 2000-2016 (valores em R\$ de março/2018)

\begin{tabular}{lccc}
\hline & Metalúrgicos - Brasil & Estado de São Paulo & Grande ABC \\
\hline 2000 & $3.280,53$ & $3.825,00$ & $5.014,59$ \\
\hline 2001 & $3.324,03$ & $3.971,89$ & $5.516,79$ \\
\hline 2002 & $3.132,03$ & $3.696,67$ & $5.105,84$ \\
\hline 2004 & $3.278,97$ & $3.887,54$ & $5.503,42$ \\
\hline 2005 & $3.288,04$ & $3.844,98$ & $5.199,82$ \\
\hline 2006 & $3.276,35$ & $3.852,79$ & $5.199,80$ \\
\hline 2007 & $3.337,36$ & $3.918,06$ & $5.079,46$ \\
\hline 2008 & $3.328,62$ & $3.893,73$ & $5.161,77$ \\
\hline 2009 & $3.442,22$ & $4.014,75$ & $5.251,68$ \\
\hline 2010 & $3.476,34$ & $4.115,32$ & $5.606,27$ \\
\hline 2011 & $3.502,86$ & $4.121,94$ & $5.603,02$ \\
\hline 2012 & $3.576,07$ & $4.207,61$ & $5.644,35$ \\
\hline 2013 & $3.605,59$ & $4.224,91$ & $5.463,54$ \\
\hline 2014 & $3.705,58$ & $4.310,03$ & $5.571,51$ \\
\hline 2015 & $3.707,38$ & $4.315,00$ & $5.345,32$ \\
\hline 2016 & $3.574,53$ & $4.194,69$ & $5.357,49$ \\
\hline
\end{tabular}

Fonte: Elaboração própria com base nos dados do MTPS da Rais Estabelecimentos dos anos selecionados ${ }^{14}$.

Esses números mostram a capacidade do sindicato de manter ou preservar, ao longo do tempo, as conquistas econômicas e o poder de compra dos salários dos operários que sobreviveram aos ajustes e à redução no número de empregos promovidos pelo processo de reestruturação industrial. A manutenção dos investimentos, por parte das empresas, se deu em contrapartida ao aumento das exigências, das jornadas de trabalho e da produtividade, o que também exigiu um trabalhador mais escolarizado.

No que diz respeito às mudanças no nível de escolaridade dos trabalhadores, percebemos um aumento

14 Disponível em: <https://bit.ly/2OAQB0n>. Acesso em: 25 jul. 2018. 
significativo, o que tem relação direta com as novas tecnologias e as exigências impostas pelas fábricas reestruturadas. Enquanto na década de 1980 o percentual dos metalúrgicos do Grande $\mathrm{ABC}$ que não tinham sequer concluído o ensino fundamental chegava a $65 \%$; em 2016, esse contingente representava apenas 5,0\%. Já aqueles com ensino médio completo que perfaziam 11\% em 1985, em 2016 chegavam a $60 \%$ da mão de obra metalúrgica e, em 1985, apenas $5 \%$ possuíam ensino superior. Já em 2016, 22\% dos metalúrgicos do ABC possuíam curso superior completo (Gráfico 2).

\section{Gráfico 2}

Escolaridade dos metalúrgicos empregados no Grande ABC (1985-2016)

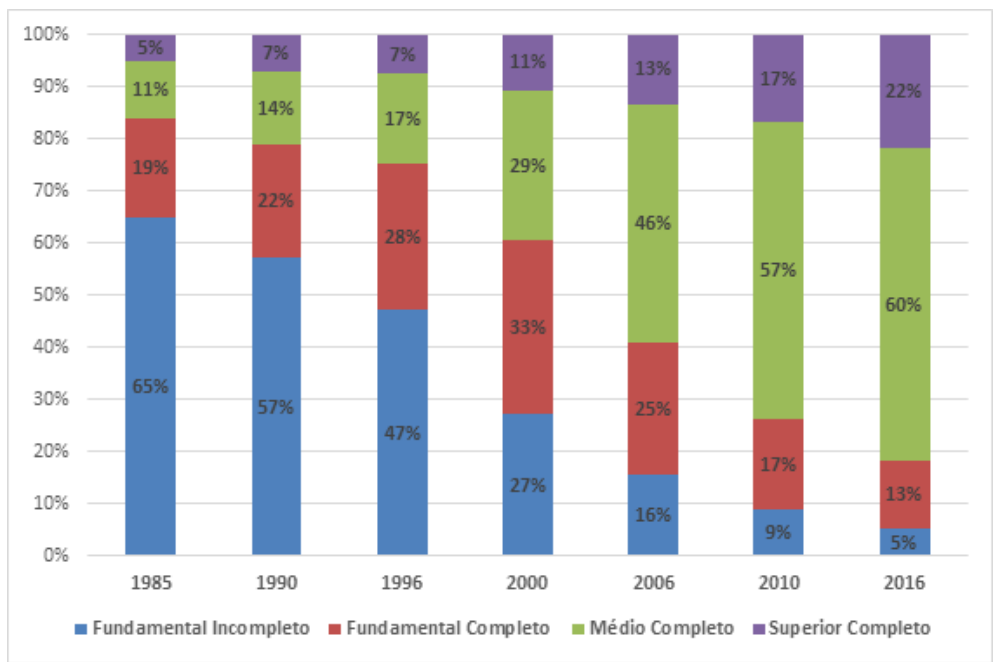

Fonte: Elaboração própria a partir de dados do MTPS da Rais - Vínculos dos anos selecionados ${ }^{15}$.

Um maior grau de escolaridade dos metalúrgicos - que reflete não só as exigências do mercado de trabalho industrial, mas também os avanços nas últimas décadas da escolaridade formal da população brasileira - e a presença maciça das grandes montadoras de automóveis e seus fornecedores nos municípios

${ }^{15}$ Disponível em: <https://bit.ly/2OAQB0n>. Acesso em: 25 jul. 2018. 
do Grande ABC também contribuíram para que as médias salariais fossem superiores às verificadas em outras regiões industriais.

A despeito da redução nos postos de trabalho, o setor da "indústria de transporte" (que agrega a automobilística e parte das autopeças) é o que mais emprega os trabalhadores metalúrgicos da região: em 1985, esse contingente representava $57 \%$ do total dos metalúrgicos e, em 2016, 51\% (vínculos ativos no dia $31 / 12$ ).

O setor automotivo, além de ser o que mais emprega, oferece também os salários mais altos: com média salarial que, em 2016, chegava a 8,2 mil reais, superava em quase três mil reais a média salarial dos metalúrgicos da região (Gráfico 3).

\section{Gráfico 3}

Salário médio dos metalúrgicos, dos empregados das montadoras, das autopeças e dos trabalhadores formais - 2000-2016

(Grande $A B C$, valores em $R \$$ de março/2018)

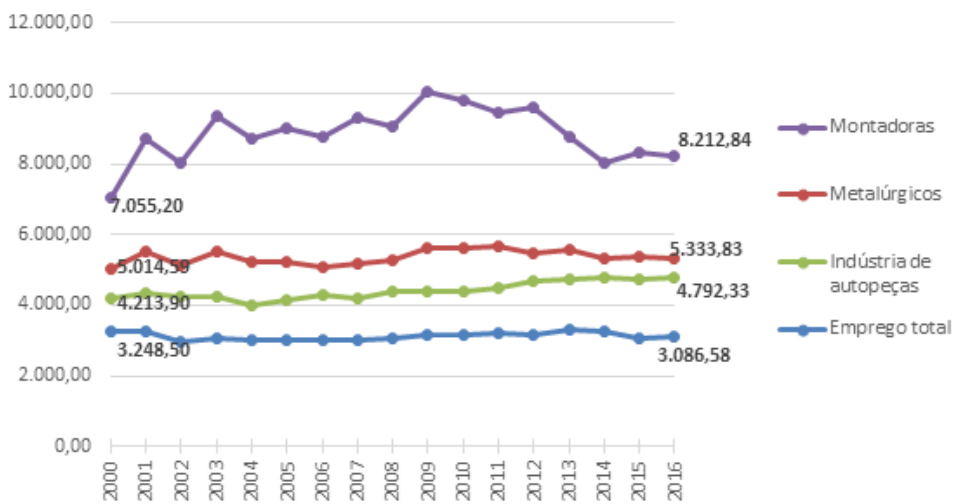

Fonte: Elaboração própria a partir de dados do Ministério do Trabalho e da Previdência Social do Rais - Vínculos dos anos selecionados ${ }^{16}$.

O crescimento das vendas de automóveis no mercado doméstico durante o governo Lula e o primeiro mandato da presidente Dilma Rousseff também fortaleceu o sindicato

${ }^{16}$ Disponível em: <https://bit.ly/2OAQB0n>. Acesso em: 25 jul. 2018. 
dos metalúrgicos do $\mathrm{ABC}$ durante as negociações salariais ${ }^{17}$. Desse modo, com exceção de 2015 - quando o mercado já sente os efeitos do desaquecimento da economia - os metalúrgicos conquistaram reajustes em todos os anos, com um aumento real acumulado de $38,7 \%$ no caso das montadoras, e de $34,0 \%$ no caso das autopeças, conforme as Tabelas 4 e 5.

Tabela 4

Reajuste salarial nas montadoras do Grande ABC (2003-2015)

\begin{tabular}{cccc}
\hline Ano & $\begin{array}{c}\text { Reajuste salarial } \\
\text { montadoras (\%) }\end{array}$ & $\begin{array}{c}\text { Inflação } \\
\text { INPC (IBGE)* }\end{array}$ & $\begin{array}{c}\text { Aumento real } \\
(\%)^{18}\end{array}$ \\
\hline 2003 & 18,01 & 17,25 & 0,41 \\
\hline 2004 & 10,00 & 6,64 & 3,15 \\
\hline 2005 & 8,75 & 5,01 & 3,56 \\
\hline 2006 & 4,19 & 2,85 & 1,30 \\
\hline 2007 & 7,66 & 4,82 & 2,71 \\
\hline 2008 & 11,01 & 7,15 & 3,60 \\
\hline 2009 & 6,53 & 4,44 & 2,00 \\
\hline 2010 & 10,81 & 4,29 & 6,25 \\
\hline 2011 & 10,00 & 7,39 & 2,43 \\
\hline 2012 & 10,00 & 5,39 & 4,37 \\
\hline 2013 & 8,19 & 6,07 & 2,00 \\
\hline 2014 & 8,00 & 6,35 & 1,55 \\
\hline 2015 & 9,88 & 9,88 & 0,00 \\
\hline Total & 222,37 & 132,31 & 38,77 \\
\hline
\end{tabular}

* Os cálculos inflacionários foram baseados nos doze meses anteriores a setembro de cada ano, quando se dá a data-base dos empregados das montadoras.

Fonte: Elaboração própria com base nos dados do Departamento Intersindical de Estatística e Estudos Socioeconômicos (Dieese). Sistema de Acompanhamento de Salários (SAS) ${ }^{19}$.

17 Segundo os dados da Associação Nacional dos Fabricantes de Veículos Automotores (Anfavea), as vendas de veículos leves no Brasil (automóveis, pick-ups e vans) saltaram de 1,3 milhão, em 2003, para mais de 3,6 milhões de unidades, em 2012 (ano recorde no volume de vendas). Em termos de faturamento anual, isso representou para a indústria uma mudança nos ganhos de 15,6 bilhões para 83,7 bilhões de dólares, acumulados somente com a venda de automóveis e pick-ups. Embora nos últimos anos tenha sido observada uma tendência de queda nas vendas do setor, no ano de 2015, mais de 2,4 milhões de novos veículos ganharam as ruas brasileiras, o que representou um faturamento anual elevado, próximo aos 75 bilhões de dólares (Associação Nacional dos Fabricantes de Veículos Automotores, 2016).

18 Como se trata de valores percentuais, o aumento real é calculado a partir da divisão entre a variação dos salários e a variação da inflação.

19 Disponível em: <https://bit.ly/1ukxyWP>. Acesso em: 25 jul. 2018. 
Tabela 5

Reajuste salarial na indústria de autopeças do Grande ABC (2003-2015)

\begin{tabular}{cccc}
\hline Ano & $\begin{array}{c}\text { Reajuste salarial autopeças, } \\
\text { forjarias e parafusos (\%) }\end{array}$ & Inflação INPC (IBGE)* & $\begin{array}{c}\text { Aumento real } \\
(\%)\end{array}$ \\
\hline 2003 & 16,16 & 16,15 & 0,01 \\
\hline 2004 & 9,57 & 5,72 & 3,64 \\
\hline 2005 & 8,00 & 5,42 & 2,44 \\
\hline 2006 & 4,90 & 2,71 & 2,13 \\
\hline 2007 & 7,44 & 4,78 & 2,54 \\
\hline 2008 & 11,01 & 7,26 & 3,50 \\
\hline 2009 & 6,53 & 4,18 & 2,26 \\
\hline 2010 & 9,00 & 5,39 & 3,42 \\
\hline 2011 & 10,00 & 6,66 & 3,13 \\
\hline 2012 & 8,00 & 4,58 & 3,27 \\
\hline 2013 & 8,00 & 6,07 & 1,82 \\
\hline 2014 & 8,00 & 6,35 & 1,55 \\
\hline 2015 & 9,88 & 9,88 & 0,00 \\
\hline Total & 204,06 & 126,85 & 34,03 \\
\hline
\end{tabular}

*Entre 2003 e 2004 os cálculos inflacionários foram baseados nos doze meses anteriores a novembro. Entre 2005 e 2007, devido a alterações na data base da categoria, o período de referência deslocou-se para os doze meses anteriores a agosto, sendo que a partir de 2008 fixou-se nos doze meses anteriores a setembro.

Fonte: Elaboração própria com base nos dados do SAS-Dieese ${ }^{20}$.

Embora o sindicato encontre dificuldades de evitar as demissões e o desemprego decorrente das inovações tecnológicas, suas lideranças se esforçam para impedir as demissões em massa e tornar as dispensas cada vez mais onerosas às empresas. No caso das montadoras é muito comum que a saída dos trabalhadores seja precedida por planos de demissão voluntária, indenizações e a manutenção por um período negociado, de um pacote de benefícios como assistência médica e vale alimentação, de modo que a saída seja menos traumática para os trabalhadores e suas famílias.

Essa estratégia, combinada com o interesse das empresas em preservar os trabalhadores mais qualificados, tende a contribuir para que haja maior retenção da mão de obra e continuidade dos vínculos. Assim, entre 1985 e 2016, os vínculos de curta

${ }^{20}$ Disponível em: <https://bit.ly/lukxyWP>. Acesso em: 25 jul. 2018. 
duração (ou seja, encerrados com menos de um ano), caem de $31 \%$ para $17,0 \%$. Por outro lado, aqueles estabelecidos há dez anos ou mais crescem: no ano de 1985 representavam $16 \%$ e, em 2016, eram 29\%. Vale dizer que, neste ano, cerca de $1 / 3$ dos trabalhadores metalúrgicos na região estavam empregados em suas respectivas empresas há dez ou mais anos.

Tabela 6

Tempo de duração dos vínculos de trabalho metalúrgico* (Grande ABC, 1985-2016)

\begin{tabular}{ccccccc}
\hline Ano & $\begin{array}{c}\text { Menos } \\
\text { de } 1 \text { ano }\end{array}$ & $\begin{array}{c}\text { De } 1 \text { a menos } \\
\text { de 3 anos }\end{array}$ & $\begin{array}{c}\text { De 3 a menos } \\
\text { de 5 anos }\end{array}$ & $\begin{array}{c}\text { De } 5 \text { a menos } \\
\text { de } 10 \text { anos }\end{array}$ & $\begin{array}{c}10 \text { anos } \\
\text { ou mais }\end{array}$ & Total \\
\hline 1985 & 83.547 & 59.481 & 28.576 & 54.552 & 41.555 & 267.710 \\
\hline & $31 \%$ & $22 \%$ & $11 \%$ & $20 \%$ & $16 \%$ & $100 \%$ \\
\hline 1990 & 63.335 & 67.375 & 42.916 & 38.308 & 41.653 & 253.587 \\
\hline & $25 \%$ & $27 \%$ & $17 \%$ & $15 \%$ & $16 \%$ & $100 \%$ \\
\hline 1996 & 30.255 & 43.726 & 15.572 & 37.113 & 43.911 & 170.576 \\
\hline & $18 \%$ & $26 \%$ & $9 \%$ & $22 \%$ & $26 \%$ & $100 \%$ \\
\hline 2000 & 27.862 & 22.754 & 15.499 & 25.400 & 37.190 & 128.704 \\
\hline & $22 \%$ & $18 \%$ & $12 \%$ & $20 \%$ & $29 \%$ & $100 \%$ \\
\hline 2006 & 34.262 & 40.652 & 16.110 & 24.697 & 41.607 & 157.328 \\
\hline & $22 \%$ & $26 \%$ & $10 \%$ & $16 \%$ & $26 \%$ & $100 \%$ \\
\hline 2010 & 53.207 & 39.957 & 20.987 & 27.206 & 43.920 & 185.277 \\
\hline & $29 \%$ & $22 \%$ & $11 \%$ & $15 \%$ & $24 \%$ & $100 \%$ \\
\hline 2016 & 21.759 & 24.051 & 15.890 & 31.523 & 38.637 & 131.860 \\
\hline & $17 \%$ & $18 \%$ & $12 \%$ & $24 \%$ & $29 \%$ & $100 \%$ \\
\hline
\end{tabular}

* Totalidade de vínculos existentes a cada ano.

Fonte: Elaboração própria com base nos dados do MTPS do RAIS - Vínculos dos anos selecionados.

Esse fato, contudo, não evitou a rotatividade, pois, apesar do crescimento dos vínculos mais duradouros, no ano de 2016 a taxa de rotatividade ainda era alta $-27 \%$ dos metalúrgicos empregados no Grande ABC foram demitidos (com ou sem justa causa), aposentaram-se ou trocaram de emprego durante o ano. Nas montadoras, o índice de rotatividade que em 2012 representava 6\%, triplica em 2016, alcançando 18\% (MTPS, RAIS, 2016). Esses dados são indicativos da implantação efetiva de relações de trabalho mais flexíveis neste tipo de indústria e em toda região. 


\section{Homens e mulheres na força de trabalho}

A elevada presença masculina na força de trabalho é outra característica marcante. Apesar de as mulheres terem aumentado sua participação no sindicato e no emprego industrial, o crescimento foi pequeno e, no ano de 2016, representavam apenas $16 \%$ do conjunto dos trabalhadores metalúrgicos - em torno de quinze mil trabalhadoras (Gráfico 4). Quando comparamos o ano de 1985 e 31 anos depois, verificamos que ocorreu uma diminuição em termos absolutos, tanto no número de metalúrgicos quanto no de metalúrgicas. No entanto, houve pequeno crescimento em termos relativos: as mulheres representavam, naquele ano, $12 \%$ e, em 2016, passaram a representar 16\%. Além disso, a média salarial feminina nas empresas metalúrgicas do Grande ABC continua inferior à masculina. No ano 2000, por exemplo, a diferença era de cerca de $\mathbf{R} \$ 1.800,00$, já em 2016, passados dezessete anos, essa diferença caiu um pouco menos de $\mathrm{R} \$ 1.000,00$ (Gráfico 5), mas manteve a defasagem salarial.

Gráfico 4

Metalúrgicos do Grande ABC segundo o sexo (1985-2016)

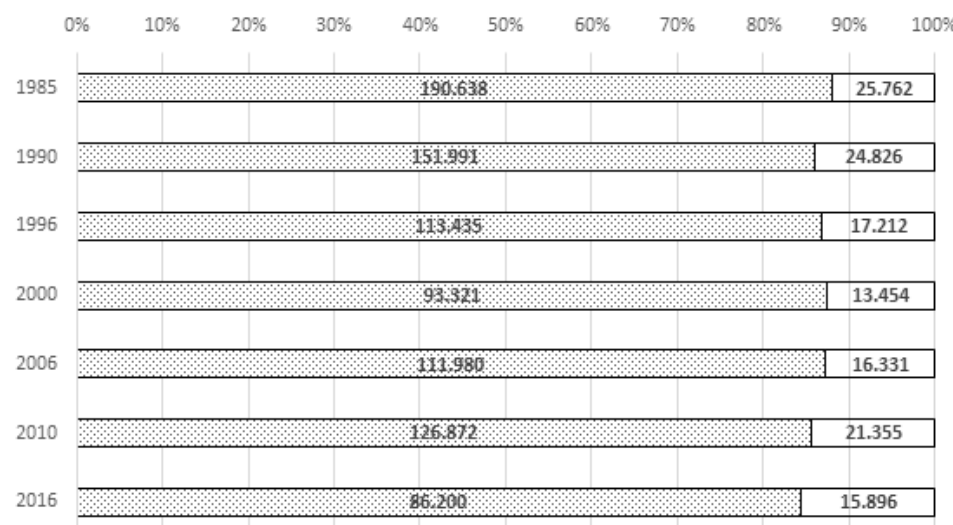

๑ Masculino aFeminino

Fonte: Elaboração própria a partir de dados do MTPS do Rais - Vínculos dos anos selecionados. 
Gráfico 5

Média salarial de homens e mulheres metalúrgico(a)s no Grande ABC

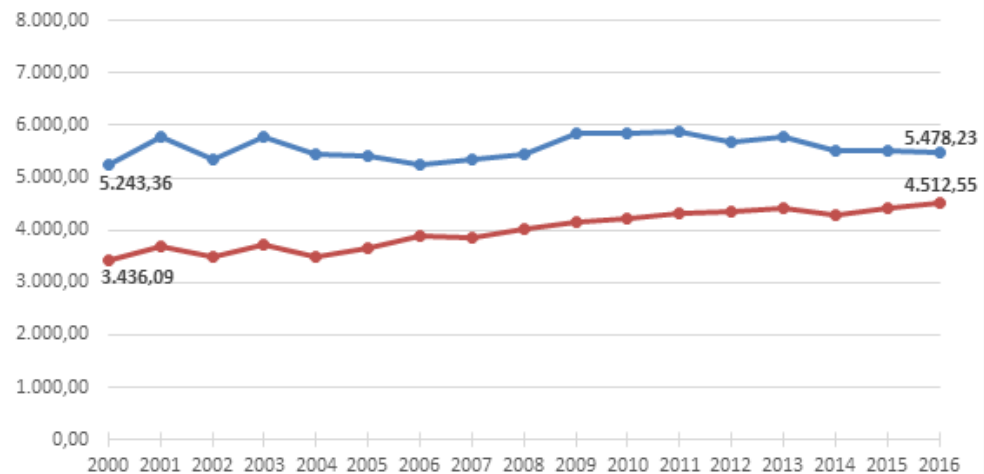

$\longrightarrow$ Masculino $\longrightarrow$ Feminino

Fonte: Elaboração própria a partir de dados do MTPS do Rais - Vínculos dos anos selecionados.

Os dados demonstram uma região industrial em transformação. A categoria metalúrgica se reduziu (de 216.400 operários em 1985, para 102.096 em 2016), mas pode-se constatar uma mudança no perfil, seja em termos de qualificação, seja em termos de escolaridade formal.

\section{Mobilização política e conquistas salariais}

Entre 2006 e 2012, houve importantes melhorias salariais num período de expansão da renda, do crédito e do mercado doméstico.

Dados referentes ao número de greves ocorridas nos municípios do Grande ABC durante os governos de Fernando Henrique Cardoso (1994-2002), Lula (2003-2010) e nos primeiros dois anos de Dilma (2011-2012), demonstram uma intensa atividade grevista, entre os anos de $1994 \mathrm{e}$ 1996, quando 316 greves ocorrem somente no Grande ABC. Esse período de grande mobilização coincide com o de estabilização monetária, de reestruturação industrial e de ameaças de fechamento e deslocamento geográfico de grandes 
empresas da região (período também do regime automotivo que estimulou e viabilizou, por meio de incentivos fiscais, a implantação de novas montadoras no país).

Os dados sobre as greves, segundo os setores industriais de sua ocorrência, revelam que a grande maioria delas ocorreu nas metalúrgicas, mecânicas e na indústria do material elétrico (incluindo as fábricas de autopeças). Tais setores são marcados pela instabilidade, estavam mais expostos à concorrência externa e, recorrentemente, seus trabalhadores conviviam com problemas de atraso de salários, de décimo terceiro, do vencimento de férias e de elevado número de acidentes de trabalho.

Gráfico 6

Número de greves metalúrgicas na região do Grande $A B C$ (governos FHC e governos Lula/Dilma)

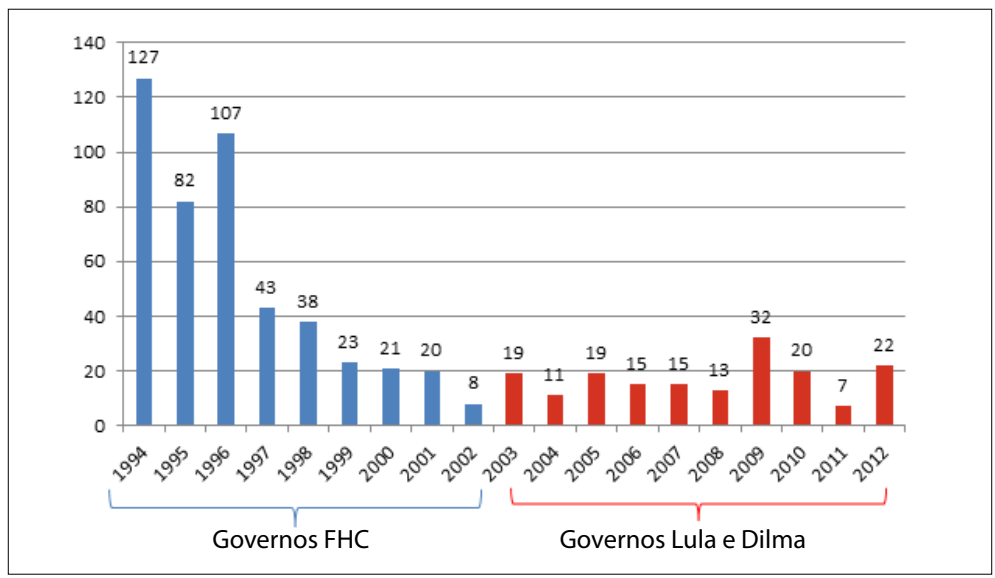

Fonte: Elaboração própria com base nos dados do Dieese, Sistema de Acompanhamento de Greves (SAG) ${ }^{21}$.

As greves e paralisações ocorridas durante o governo Lula indicam um tipo de demanda que se enquadrava na pauta de questões mais gerais sobre a economia e o país.

${ }^{21}$ Disponível em: <https://bit.ly/1ukxyWP>. Acesso em: 25 jul. 2018. 
Em 2007, houve uma paralisação geral dos metalúrgicos em função dos protestos e manifestações contrárias à proposta de Emenda Constitucional n 3, que tentava regulamentar e ampliar a prestação de serviços de terceiros e pessoas jurídicas para além das atividades auxiliares. Após dois dias de protestos, com marcha de trabalhadores e visitas a parlamentares em Brasília, a proposta foi engavetada.

Tabela 7

Número de greves metalúrgicas na região do Grande $A B C$ segundo o setor industrial (governos FHC e governos Lula/Dilma)

\begin{tabular}{ccccc}
\hline & $\begin{array}{c}\text { Metalúrgicas, mecânicas } \\
\text { e do material elétrico }\end{array}$ & $\begin{array}{c}\text { Indústria } \\
\text { automobilística }\end{array}$ & $\begin{array}{c}\text { Greve } \\
\text { geral }\end{array}$ & Total \\
\hline FHC 1994-1997 & 326 & 32 & 1 & 359 \\
\hline FHC 1998-2002 & 59,5 & 34,4 & 100,0 & 55,9 \\
\hline & 74 & $36^{2}$ & 0 & 110 \\
\hline Lula 2003-2006 & 13,5 & 38,7 & 0,0 & 17,1 \\
\hline Lula 2007-2010 & 48 & 16 & 0 & 64 \\
\hline & 8,8 & 17,2 & 0,0 & 10,0 \\
\hline Dilma 2011-2012 & 72 & 8 & 0 & 80 \\
\hline & 13,1 & 8,6 & 0,0 & 12,5 \\
\hline Total & 28 & 1 & 0 & 29 \\
\hline & 5,1 & 1,1 & 0,0 & 4,5 \\
\hline
\end{tabular}

Fonte: Elaboração própria com base nos dados do Dieese, Sistema de Acompanhamento de Greves (SAG).

Com exceção das greves e paralisações que ocorreram durante as campanhas salariais no período Lula (somente em 2007 e 2010 não houve paralisações durante as campanhas salariais), a maior parte das atividades grevistas referia-se às demandas dos trabalhadores de uma única empresa.

Entre as montadoras, os trabalhadores da Volkswagen (Rodovia Anchieta) se destacaram no período Lula, durante 
as greves de resistência ocorridas em 2003, à tentativa da empresa de se reestruturar e transferir 1.923 trabalhadores ao Projeto Autovisão, que, diferentemente de sua versão alemã - que desenvolveu uma série de atividades e atrações turísticas que revitalizaram e geraram empregos na cidade de Wolfsburg (Ramalho, 2010) - por aqui foi apresentado como um programa de demissão voluntária, transferência da mão de obra às empresas de prestação de serviços e a programas de qualificação e aperfeiçoamento profissional. Após a resistência e duras negociações, que envolveram até o envio de representantes sindicais à Alemanha, os trabalhadores conseguiram fazer um acordo que, além de ampliar os incentivos à demissão (40\% do salário por ano trabalhado, verbas rescisórias e mais vinte salários nominais), garantiu a qualificação remunerada (com todos os benefícios e reajustes) aos empregados afastados até o primeiro semestre de $2006^{22}$.

Contudo, ao final do compromisso de garantia do emprego (em agosto de 2006), a montadora promoveu uma nova investida contra os trabalhadores com a demissão por carta de 1.800 empregados em um único dia ${ }^{23}$. Dessa vez, apesar de conquistarem um novo acordo de PDV - por meio de uma nova greve de quinze dias e da suspensão do financiamento do Banco Nacional do Desenvolvimento Econômico e Social (BNDES) por parte do Governo Federal - as 1.063 adesões não atenderam às expectativas da empresa e uma pequena parte dos trabalhadores acabou sendo demitida.

A retomada das contratações por parte da Volkswagen ocorreu apenas a partir de maio de 2007 quando as medidas de incentivo do Governo Federal, como a expansão do crédito e a redução do IPI e o lançamento de novos produtos pela montadora aumentaram as suas vendas e a sua

\footnotetext{
${ }^{22}$ Cf. Tribuna Metalúrgica de 2/10/2003. Disponível em: <https://bit.ly/2vtDyFl $>$. Acesso em: 26 jul. 2018.

${ }^{23}$ Cf. Tribuna Metalúrgica de 30/08/2006. Disponível em: <https://bit.ly/2OAQMc3>. Acesso em: 26 jul. 2018.
} 
participação no mercado nacional. Nesse período, a empresa reincorporou ao chão de fábrica boa parte dos trabalhadores anteriormente afastados. O nível de emprego, no entanto, jamais retornou aos patamares anteriores à reestruturação ${ }^{24}$.

\section{Conclusão}

A proximidade do sindicato dos metalúrgicos do $\mathrm{ABC}$ com o governo federal durante o período em que seu representante máximo ocupava o cargo de presidente da República pode ser objeto de diferentes tipos de avaliação. O levantamento de dados sobre as atividades econômicas e o mercado de trabalho na região revelam que os trabalhadores - em especial os metalúrgicos - foram diretamente afetados pelas estratégias macroeconômicas das grandes empresas multinacionais, com a redução do número de empregos e a flexibilização das relações de trabalho.

Por outo lado, a força da organização acumulada pelo 94 sindicato desde os tempos da ditadura, nas greves de 1978, 1979 e 1980, e consolidada pelo trabalho de base realizado dentro das fábricas, permitiu conquistas na negociação de aumentos reais de salário e se estendeu para o mundo da política e da economia, de modo mais geral, pelas campanhas de valorização do salário mínimo, da defesa de políticas sociais voltadas às populações mais desprotegidas, da luta por reconhecimento legal da representação sindical (caso do reconhecimento legal das centrais sindicais, em 2008) e pela demanda de participar de instâncias nacionais e regionais de definição de estratégias de desenvolvimento econômico.

Não se pode desconsiderar, na avaliação desse período de proximidade do sindicato (e do sindicalismo) com governos de perfil trabalhista, que as perdas e ganhos para os trabalhadores organizados ou não estão marcadas pelas conjunturas e

${ }^{24}$ Cf. Tribuna Metalúrgica de 22/11/2006; 29/05/2007; 12/07/2007 e 27/11/2007. Disponíveis em: <https://bit.ly/2OxVYxv>. Acesso em: 26 jul. 2018. 
pelos contextos nos quais a política e a economia se articulam em termos nacionais e internacionais. É preciso lembrar que, como dizem Hyman e Gumbrell-McCormick (2010, p. 315), os "sindicatos não são apenas atores econômicos: eles são necessariamente protagonistas na arena política"; e que sua participação na defesa dos direitos dos trabalhadores permanece como aspecto central na vida econômica e política do país.

\section{José Ricardo Ramalho}

é professor do Departamento de Sociologia e do Programa de Pós-Graduação em Sociologia e Antropologia da Universidade Federal do Rio de Janeiro (PPGSA-UFRJ).

\section{Iram Jácome Rodrigues}

é professor do Departamento de Economia e do Programa de Pós-Graduação em Sociologia da Universidade de São Paulo (PPGS-USP). É pesquisador do Conselho Nacional de Desenvolvimento Científico e Tecnológico (CNPq).

\section{Bibliografia}

ANDERSON, Perry. 2011. O Brasil de Lula. Novos Estudos Cebrap, v. 30, n. 3, pp. 23-52.

CARDOSO, Adalberto. 2016. Tomorrow you will be the government: the Vargas's utopia in practice. In: CARDOSO, Adalberto. Work in Brazil: essays in historical and economic sociology. Rio de Janeiro: Eduerj. pp. 99-137.

CONCEIÇÃO, Jefferson José. 2008. Quando o apito da fábrica silencia. São Bernardo do Campo: ABCD Maior.

FAIRBROTHER, Peter; WEBSTER, Edward. 2008. Social moviment unionism: questions and possibilities. Employee Responsabilities and Rights Journal, n. 20, pp. 309-313.

FORTES, Alexandre; FRENCH, John. 2012. A "Era Lula", as eleições presidenciais de 2010 e os desafios do pós-neoliberalismo. Tempo Social, v. 24, n. 1, pp. 201-228.

HYMAN, Richard; GUMBRELL-MCCORMICK, Rebecca. 2001.

Understanding European Trade Unionism: between market, class and society. London: Sage. 
2010. Trade unions, politics and parties: is a new configuration possible? Transfer, v. 16, n. 3, pp. 315-331.

OLIVEIRA, Roberto Véras. 2011. Sindicalismo e democracia no Brasil: do novo sindicalismo ao sindicato cidadão. São Paulo: Annablume.

RAMALHO, José Ricardo. 2010. Flexibilidade e crise do emprego industrial: sindicatos, regiões e novas ações empresariais. Sociologias, v. 12, n. 25, pp. 252-284.

RAMALHO, José Ricardo; RODRIGUES, Iram Jácome. 2010. Sindicato, crise econômica e estratégias regionais: novas dimensões da participação política no ABC Paulista. Caderno CRH, v. 23, n. 59, pp. 339-351.

2013. Sindicato, desenvolvimento e trabalho. Caderno $C R H$, v. 26, n. 68 , pp. $217-231$.

RAMALHO, José Ricardo; RODRIGUES, Iram Jácome; CONCEIÇÃO, Jefferson José. 2009. Reestruturação industrial, sindicato e território: alternativas políticas em momentos de crise na região do ABC em São Paulo, Brasil. Revista Crítica de Ciências Sociais, n. 85, pp. 147-167.

RODRIGUES, Iram Jácome (org.). 1995. O sindicalismo brasileiro: da confrontação à cooperação conflitiva. São Paulo em Perspectiva, n. 9, pp. 116-126. 1999. O novo sindicalismo: vinte anos depois. Petrópolis: Vozes. 2006. A dimensão regional da ação sindical: os metalúrgicos do

ABC. Estudos de Sociologia, v. 11, n. 21, pp. 73-96. 2011. Sindicalismo e política: a trajetória da CUT (1983 a 1993). São Paulo: LTr.

RODRIGUES, Iram Jácome; RAMALHO, José Ricardo. 2009. O sindicalismo metalúrgico em contextos de reestruturação: o caso do ABC Paulista e as novas estratégias sindicais. In: LEITE, Marcia de Paula; ARAÚJO, Angela Maria Carneiro (orgs.). O trabalho reconfigurado: ensaios sobre Brasil e México. São Paulo: Annablume, pp. 243-260.

RODRIGUES, Leôncio Martins. 1999. Destino do sindicalismo. São Paulo: Edusp.

SCOTT, Allen. 2000. Revitalização industrial nos Municípios do ABC, São Paulo. Santo André: Agência de Desenvolvimento Econômico do Grande ABC.

SINGER, André. 2009. Raízes sociais e ideológicas do lulismo. Novos Estudos Cebrap, n. 85, pp. 83-102.

WATERMAN, Peter. 1999. The new social unionism: a new union model for a New World Order. In: MUNCK, Ronaldo; WATERMAN, Peter (eds.). Labour worldwide in the era of globalization. London: Macmillan, pp. 247-264. 


\section{SINDICALISMO DO ABC E A ERA LULA: CONTRADIÇÕES E RESISTÊNCIAS}

JOSÉ RICARDO RAMALHO

IRAM JÁCOME RODRIGUES

Resumo: O sindicalismo metalúrgico do ABC Paulista criou, a partir do enfrentamento político e das greves durante o período da ditadura militar de 1964, condições para defender suas demandas econômicas na esfera pública, ao mesmo tempo em que se constituiu em uma força política no cenário nacional. A eleição de Luiz Inácio Lula da Silva para a Presidência da República do Brasil, em 2002, e sua permanência no cargo por oito anos (2003-2010), foi a confirmação da força política desse sindicalismo que estabeleceu novos parâmetros e influenciou os rumos da organização dos trabalhadores no país. $\mathrm{O}$ artigo busca - a partir de um levantamento de dados estatísticos referentes ao trabalho e ao emprego na região do ABC Paulista estabelecer uma relação entre o contexto econômico e político do período Lula/Dilma Rousseff e as estratégias sindicais dos metalúrgicos, levando em conta as ligações políticas evidentes com o governo do Partido dos Trabalhadores, principalmente com o presidente operário. A intenção é avaliar, como resultado dessa proximidade, a existência de avanços e/ou recuos nas práticas de luta do sindicato no sentido de obter melhores salários, criar novas oportunidades de emprego, aumentar a atuação junto à sociedade civil e buscar interferir no debate sobre estratégias de desenvolvimento regional.

Palavras-chave: Sindicalismo; ABC Paulista; Metalúrgicos; Trabalho; Lula.

\section{TRADE UNIONISM OF THE ABC DURING THE LULA ERA: CONTRADICTION AND RESISTANCE}

Abstract: Since the political confrontation and strikes during the 1964 Brazilian military dictatorship, the metalworker trade unionism of the ABC has created viable conditions of defending its 
economic demands in the public sphere, and at the same time has become a political force in Brazil. The election of Lula in 2002 and his permanence in this position for eight years (2003-2010) were the confirmation of the political strength of this trade unionism, which established new parameters and influenced in the organization of the workers in the country. Based on statistical data collection on work and employment in the $A B C$ region, this paper seeks to determine an association between the economic and political context of the Lula/Dilma period and the strategies of the metalworkers trade union, taking into account its clear political relationship with the Brazilian Workers' Party, especially with a worker president. The objective is to evaluate, as a result of this relationship, the existence of advancements or regressions in the union's struggles for better wages, new job opportunities, approximating themselves to civil society, and its attempt to interfere in the debate about regional development strategies.

Keywords: Trade Unionism; ABC Paulista; Metalworkers; Work; Lula.

Recebido: 19/06/2018 Aprovado: 06/07/2018 